\title{
Assumptions, Empirical Evidence and Social Science Method
}

\section{Fred S. McChesney†}

As I understand them, Jeffrey Gordon and Lewis Kornhauser ${ }^{1}$ essentially argue that Jon Macey and $\mathrm{I}^{2}$ tried to make a "case" for greenmail, but that we failed. Our model, they say, makes certain assumptions. ${ }^{3}$ Having explored these assumptions, Gordon and Kornhauser conclude that "the case for [greenmail] is 'not proved." "' Gordon and Kornhauser proceed to show in detail why they believe our assumptions are "implausible," identify circumstances that are "highly unlikely"s or "extremely limited," and define instances that may "arise strictly by chance."

I find the Gordon and Kornhauser objections curious on several grounds. To begin with, we took pains in our article to stress that we were not trying to make a general case for greenmail. At the outset, we summarized our position:

Our argument is not that greenmail is never abused or that unacceptable agency costs are never imposed. Ours is an "advocacy piece" only in the sense that we believe the different reasons for paying greenmail, including those beneficial to shareholders, need to be distinguished. To avoid repeated qualification, we admit from the start that some aspects of the greenmail process remain unexplained ....

$\dagger$ John M. Olin Visiting Fellow in Law and Economics, University of Chicago Law School; Associate Professor, Emory University School of Law. A.B., Holy Cross College; J.D., University of Miami; Ph.D. (Economics), University of Virginia. Unfortunately, conflicting travel schedules and other commitments prevented Professor Macey and me from producing a joint reply to the Comment by Professors Gordon and Kornhauser. The Yale Law Journal graciously permitted us to file separate replies. Having read Macey's paper, I now concur with his observations and incorporate them by reference into my own reply.

1. Gordon \& Kornhauser, Takeover Defense Tactics: A Comment on Two Models, 96 YALE L.J. 295 (1986).

2. Macey \& McChesney, A Theoretical Analysis of Corporate Greenmail, 95 YALE L.J. 13 (1985).

3. Gordon \& Kornhauser, supra note 1, at 297.

4. Id.

5. Id. at 318.

6. Id. at 319.

7. Id.

8. Id. at 320 .

9. Macey \& McChesney, supra note 2, at 16. 
We concluded on the same note: "We have not proven that greenmail is always 'good,' simply that it need not be 'bad.'

There is nothing in the Gordon and Kornhauser comment that changes our conclusion. Gordon and Kornhauser believe that the circumstances under which greenmail will be beneficial to shareholders are few. This question is empirical, as they admit. ${ }^{11}$ Yet they present no data to support their assertions.

Indeed, Gordon and Kornhauser virtually ignore an entire section of our article that summarized the sophisticated statistical studies on greenmail appearing recently. ${ }^{12}$ Here again, our conclusions were modest. The empirical studies, we said, are "far from conclusive."1s But as the best evidence assembled so far, they indicate that many firms have in fact benefitted from raiders who buy into a firm only to be greenmailed off.

The statistical work indicates that the universal condemnation of greenmail prevailing prior to our article ${ }^{14}$ is inappropriate. This remains our sole point. Yet from Gordon and Kornhauser's comment, a reader would never suspect that a large body of evidence exists to answer the question that they concede is an empirical one. Even worse, Gordon and Kornhauser mischaracterize the evidence in their two brief allusions to it. ${ }^{15}$ And perhaps worst of all, they totally misrepresent what Macey and I said about the empirical work. ${ }^{16}$

Finally, as a strictly logical matter, I do not understand how an empiri-

10. Id. at 60 .

11. Gordon \& Kornhauser, supra note 1, at $296 \mathrm{n} .5$ ("The question is to a great extent an empirical one....").

12. Macey \& McChesney, supra note 2, at $43-48$.

13. Id. at 47.

14. For a short discussion of popular attitudes condemning greenmail, see id. at $\mathbf{1 4}$.

15. Gordon and Kornhauser state that "[t]he evidence shows that greenmail leads, in the aggregate, to shareholder welfare losses." Gordon \& Kornhauser, supra note 1, at 320; see also id. at 312, n.47. They provide no citation for this claim. In fact, the evidence indicates just the reverse when one takes account of the entire sequence of a greenmailer's purchase of shares and his later sale back to the firm. This point is discussed with specific reference to the various studies in Macey \& McChesney, supra note 2 , at $43-44$.

16. Gordon and Kornhauser say that our analysis is "motivated by a misunderstanding of the empirical literature on greenmail." Gordon \& Kornhauser, supra note 1, at 312 n.47. Our sin was an alleged failure to understand that "[a]verages are critical in this process" of comparing positive and negative price changes for firms paying greenmail. Id. But Macey and I discuss this very point quite clearly. One must realize, we note, "that the studies report average price changes." Macey \& McChesney, supra note 2 , at 47 (emphasis in original). We then discussed the implications of this fact.

Gordon and Kornhauser also characterize Macey and me as "[c]onceding that the literature shows that on average losses outweigh gains" to firms paying greenmail. Gordon \& Kornhauser, supra note 1 , at 312 n.47. Gordon and Kornhauser thus would put into our mouths the same misstatement that they make about the empirical work. The empirical studies show exactly the opposite, that allowing a greenmailer to buy a minority stake in a firm and then be greenmailed off on average benefits the firm paying greenmail. See supra note 15. Thus Macey and I hardly "concede[d]" that the losses outweigh the gains overall; we noted repeatedly that the reverse is true. Macey \& McChesney, supra note 2, at 44-47. 
cal debate can be resolved by questioning an opponent's assumptions. Even were our assumptions as implausible and unlikely as Gordon and Kornhauser assert, this claim hardly refutes the empirical evidence that many firms benefit from paying greenmail. Of course, had Gordon and Kornhauser acknowledged the evidence, they could hardly have justified their conclusion that greenmail "should not be permitted as a defensive tactic."17

The Gordon and Kornhauser comment purports to be an addition to the ongoing debate in economics and finance about resistance to takeover offers. Ultimately, how one evaluates Gordon and Kornhauser's points will depend on one's understanding of scientific method in social science. ${ }^{18}$ In principle, scientific method involves specification of assumptions, construction of a model, derivation of statistically testable implications of the model, and empirical testing. A model validated empirically is never proclaimed the immutable truth. It is tentatively deemed not refuted, and then applied where useful until a better model is presented to refute it. Refutation requires a new theoretical model, testable implications that distinguish the newer from the older model, and statistical verification that the newer model out-performs the older one.

Gordon and Kornhauser limit themselves to unsupported assertions about our assumptions. They provide neither alternative hypotheses nor tests that would lead readers to reject our model. They present no data, and they largely ignore the considerable body of evidence we discussed in our article. Thus it is hard to see how the Gordon and Kornhauser comment adds to, or for that matter even joins, the ongoing social science debate.

17. Gordon \& Kornhauser, supra note 1, at 297. It is interesting that even those empiricists whose work provides the best evidence that greenmail is unwise believe that their findings are only weak support for the agency cost model that Gordon and Kornhauser embrace. See Macey \& McChesney, supra note 2, at 43-44 \& n.103.

18. See Friedman, The Methodology of Positive Economics, in Readings in Microeconomics (W. Breit \& H. Hochman.2d ed. 1971). 